\title{
Pathogenic identification and antibiotic susceptibility of the microorganisms isolated from urine samples of UTI patients
}

\author{
Md. Ibrahim Miah, Tasnia Ahmed and Saurab Kishore Munshi* \\ Department of Microbiology, Stamford University Bangladesh, 51 Siddeswari Road, Dhaka 1217, Bangladesh
}

Received 22 July 2016/Accepted 11 October 2016

\begin{abstract}
Urinary tract infection (UTI) is the infection that occurs in the urinary tract by the invasion of pathogenic bacteria, fungi, virus etc. under some circumstances only. Some common pathogenic bacteria associated with UTI include Escherichia coli, Proteus spp., Streptococcus spp., Staphylococcus spp., Pseudomonas spp. In the ongoing research work, about 30 UTI patients were selected randomly to detect the pathogen responsible for causing urinary tract infection and also to demonstrate their drug resistant traits. Among the 30 samples, about 14 samples were found to harbor Proteus spp. $\left(1 \times 10^{4} \mathrm{cfu} / \mathrm{ml}^{\text {to }} 1 \times 10^{5} \mathrm{cfu} / \mathrm{ml}\right)$. Escherichia coli was found to be the second predominant agent for UTI and recovered from 13 samples. Among the rest 3 samples, Pseudomonas spp. was found in 2 samples and Klebsiella spp. was found in one sample. Identified isolates showed resistance against different ranges of antibiotics. The study findings revealed the fact that emerging drug resistance of different pathogenic bacteria could become the major difficulties in the treatment of infectious diseases like UTI.
\end{abstract}

Key words: Urinary tract infection; Pathogenic bacteria, Antibiotic resistance

Urinary tract infection (UTI) is a common global problem and one of the major causes for which patients seek for medical treatments. Approximately 250 million people world-wide get infected with UTI (1-6). Females are more prone to UTI because of the easier and shorter access from the external of the urethra to the urinary bladder than the males who have much longer urethra. Females also get UTI easily during sexual intercourse and child birth $(7,8)$. The rate of UTI depends on age, sex, immune status, catheterization etc. Urinary tract infections are mainly caused by bacteria and occasionally by fungi and viruses. Most common bacteria causing such infections include Escherichia coli, Klebsiella spp., Proteus spp., Pseudomonas spp., Streptococcus spp., Staphylococcus spp., Neisseria spp. etc $(7,9,10)$. Despite of many antibacterial mechanisms in the urinary bladder to have infection, the uropathogenic bacteria can invade such mechanisms and colonize in the urinary tract to start an infection (11-15). Different tests are in use to detect UTI such as urinalysis, Gram staining, urine culture and so on (15).

The treatment starts with the result of antibiotic resistance of the identified pathogen from urine sample of the patient. The physician prescribes the susceptible antibiotics from the result chart but the condition gets worse when patients use uncontrolled dosage without becoming aware of the drug resistant threats (14-27).

${ }^{*}$ Corresponding Author: Mailing address. Saurab Kishore Munshi, Department of Microbiology, Stamford University Bangladesh, 51 Siddeswari Road, Dhaka 1217, Bangladesh, Bangladesh; E-mail: kishore016@yahoo.com.
Immuno-compromised patients are at a great risk of UTI and the drug resistant traits of the pathogens makes the phenomenon even more complicated. HIV infection, diabetes, patients undergoing surgery, organ transplant patients can easily caught by UTI $(28,29)$.

In the current study 30 patients were randomly selected seeking medical facilities and supposed to have urinary tract infection. Pathogenic bacterial identification along with their count was determined in this study. In the later part of the study, antibiotic drug susceptibility test was performed for the pathogenic isolates collected from the individual patients. Sensitive, moderate and resistant antibiotic drug list was prepared for the pathogenic isolates separately to get complete array of drug susceptibility result which will help to treat the patients with the best suited susceptible antibiotic.

\section{MATERIALS AND METHODS}

Study population and sampling. Suspected urinary tract infection (UTI) patients of various ages (ranging from 14 years to 66 years old) seeking for medical treatment were considered as a study population in this study. About 30 patients were randomly selected who came for microbiological analysis in the Dhaka locality. The study was conducted from March, 2016 to May, 2016. Urine samples were collected aseptically from the mid stream in the sterile bottles provided by the test centers and immediately transferred to different culture media. Standard laboratory procedures were strictly maintained to avoid any hazards and transmissions to healthcare workers and to others (14-16).

Determination of pathogenic bacteria responsible for the urinary tract infection. After collection of urine samples, they were inoculated onto MacConkey agar plates and CLED (cysteine-, lactose- and electrolyte-deficient) agar plates to detect mostly Gram negative bacteria (14-16). An aliquot of $10 \mu 1$ sample was spread over both the types of agar plates and incubated at $37{ }^{\circ} \mathrm{C}$ for 24 hours. After incubation period, the colonies were enumerated and subjected to biochemical identification.

Antibiotic susceptibilityity of the isolated pathogens. Pathogenic bacteria 
found in the urine samples were further subjected to determine their antibiotic sensitivity patterns against the commonly prescribed antibiotics (14-16, 21).

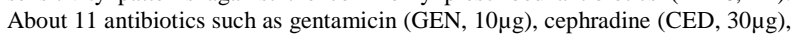

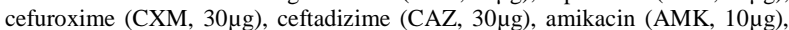
nitrofurantoin (NIT, 300 $\mu \mathrm{g}$ ), ciprofloxacin (CIP, $05 \mu \mathrm{g}$ ), levofloxacin (LE, 5 $\mu \mathrm{g}$ ), rifampin (RIF, $05 \mu \mathrm{g}$ ), ceftriaxone (CTR, $30 \mu \mathrm{g}$ ), cotrimoxazole (COT, 25 $\mu \mathrm{g})$ were selected to be tested for this study. At first, Mueller Hinton agar plates were used to make lawn of the isolated pathogenic bacterial culture and the selected antibiotic discs were placed over the lawn culture. Afterwards, the plates were incubated at $37^{\circ} \mathrm{C}$ for 24 hours. Following incubation, the plates were observed for the zone of inhibition around the antibiotic discs.

\section{RESULTS AND DISCUSSIONS}

Urinary tract infection has remained to be one of the prominent medical complications worldwide. Urinary tract is usually sterile but accidental bacterial invasion can occur causing upper and lower urinary tract infection which can be both symptomic or asymptomic (8, 11-33). Gram negative bacteria Escherichia coli and Klebsiella spp. are found to be the most common causes of UTI (14-16, 31-36). Staphylococcus aureus and Klebsiella spp. has also been reported in the urine samples of UTI patients (14-16, 37-42). In the present study, the most prevalent pathogenic bacteria were Proteus spp. and Escherichia coli which was found to be present in 14 samples and 13 samples, respectively out of 30 samples ranging from $10^{4} \mathrm{cfu} / \mathrm{ml}$ to $10^{5}$ $\mathrm{cfu} / \mathrm{ml}$. Pseudomnas spp. was found to be present in 2 samples $\left(1.5 \times 10^{4} \mathrm{cfu} / \mathrm{ml}\right.$ and $\left.2.2 \times 10^{5} \mathrm{cfu} / \mathrm{ml}\right)$ and
Klebsiella spp. was present only in one sample $\left(1.8 \times 10^{4}\right.$ $\mathrm{cfu} / \mathrm{ml})$.

In the later part of the study, microbial resistance and sensitivity towards the commonly consumed antibiotics were experimented to understand the current conditions of the medical treatments and the risks caused by the drug resistance bacteria. This approach helps the physicians to prescribe the patients to use sensitive antibiotics with appropriate dosage. But the alarming situation is that the rapidly increasing drug resistance has made the treatment of patients a big challenge (14-16). More and more pathogenic bacteria are becoming resistant and seeking and developing new sensitive drugs is a must to recover such conditions (14-21).

Bacteria can become resistant by following a variety of mechanisms which help them to avid the deleterious effects of antibiotics. Mutation is a common way of developing drug resistance. Neisseria gonorrhoeae shows resistance towards cefixime and ceftriaxone caused by ribosomal mutation (43). Pseudomonas aeruginosa has multidrug efflux mechanism to survive in the presence of antibiotics (44-47). Methicillin resistant Staphylococcus areus is a common pathogen in the whole world (48).

Many deaths have been reported due to methicillin resistant $S$. aureus $(49,50)$. Multidrug resistant pathogenic bacteria cause serious health problems in the immunecompromised patients which encourages secondary and

TABLE 1. Pathogenic microbial load (cfu/ml) in urine samples

\begin{tabular}{ccccc}
\hline \multirow{2}{*}{ Sample No } & \multicolumn{2}{c}{ Microbial load (cfu/ml) } & \\
\cline { 2 - 5 } & Escherichia coli & Proteus spp. & Klebsiella spp. & Pseudomonas spp. \\
\hline 01 & $1.1 \times 10^{5}$ & 0 & 0 & 0 \\
02 & $1.0 \times 10^{4}$ & 0 & 0 & 0 \\
03 & $1.7 \times 10^{4}$ & 0 & 0 & 0 \\
04 & 0 & $1.4 \times 10^{4}$ & 0 & 0 \\
05 & $1.5 \times 10^{5}$ & 0 & 0 & 0 \\
06 & 0 & $1.3 \times 10^{5}$ & 0 & 0 \\
07 & 0 & $2.0 \times 10^{4}$ & 0 & 0 \\
08 & 0 & $2.2 \times 10^{4}$ & 0 & 0 \\
09 & 0 & $2.7 \times 10^{5}$ & 0 & 0 \\
10 & $2.0 \times 10^{4}$ & 0 & 0 & 0 \\
11 & $1.9 \times 10^{5}$ & 0 & 0 & 0 \\
12 & 0 & $3.7 \times 10^{4}$ & 0 & 0 \\
13 & 0 & 0 & $1.8 \times 10^{4}$ & 0 \\
14 & 0 & $2.4 \times 10^{5}$ & 0 & 0 \\
15 & 0 & $2.2 \times 10^{5}$ & 0 & 0 \\
16 & $3.0 \times 10^{5}$ & 0 & 0 & 0 \\
17 & 0 & $1.8 \times 10^{5}$ & 0 & 0 \\
18 & 0 & $1.5 \times 10^{4}$ & 0 & $1.5 \times 10^{5}$ \\
19 & 0 & 0 & 0 & 0 \\
20 & $2.2 \times 10^{4}$ & 0 & 0 & 0 \\
21 & $3.1 \times 10^{5}$ & 0 & 0 & 0 \\
22 & 0 & $1.3 \times 10^{5}$ & 0 & 0 \\
23 & 0 & $1.5 \times 10^{5}$ & 0 & 0 \\
24 & $2.5 \times 10^{4}$ & 0 & 0 & 0 \\
25 & 0 & $1.4 \times 10^{4}$ & 0 & 0 \\
26 & 0 & 0 & 0 & 0 \\
27 & 0 & 0 & 0 & 0 \\
28 & $1.7 \times 10^{5}$ & 0 & 0 & 0 \\
29 & $1.7 \times 10^{5}$ & $0.2 \times 10^{5}$ & 0 \\
30 & $1.3 \times 10^{4}$ & 0 & 0 & 0 \\
\hline
\end{tabular}


TABLE 2. Antibiotic susceptibility pattern of the pathogenic bacterial isolates

\begin{tabular}{|c|c|c|c|c|}
\hline \multirow{2}{*}{ Sample No } & \multirow{2}{*}{$\begin{array}{l}\text { Bacterial } \\
\text { isolate }\end{array}$} & \multicolumn{3}{|c|}{ Antibiotic Susceptibility from urine sample } \\
\hline & & Sensitive & Moderate & Resistant \\
\hline 1 & E. coli & $\mathrm{LE}^{+}$ & & $\begin{array}{l}\text { GEN,CAZ,CIP,NIT,AMK,CXM,CED,CTR, } \\
\text { COT,RIF }\end{array}$ \\
\hline 2 & E. coli & $\mathrm{GEN}^{+}$ & COT & $\begin{array}{l}\text { CAZ,CIP,LE,NIT,AMK,CXM,CED,CTR, } \\
\text { „RIF }\end{array}$ \\
\hline 3 & E. coli & $\mathrm{GEN}^{+}$ & & $\begin{array}{l}\text { CAZ,CIP,LE,NIT,AMK,CXM,CED,CTR,C } \\
\text { OT,RIF }\end{array}$ \\
\hline 4 & Proteus spp. & $\mathrm{LE}^{+} \mathrm{GEN}^{+}$ & & $\begin{array}{l}\text { CAZ,CIP,NIT,AMK,CXM,CED,CTR,COT, } \\
\text { RIF }\end{array}$ \\
\hline 5 & E. coli & LE+ GEN+ NIT+++ & CED & CAZ,CIP,AMK,CXM, CTR,COT,RIF, NIT \\
\hline 6 & Proteus spp. & $\mathrm{LE}+\mathrm{GEN}+\mathrm{NIT}+++\mathrm{CAZ}+++$ & CED, CXM & CIP,AMK,CTR,COT,RIF \\
\hline 7 & Proteus spp. & LE,CIP & CXM & GEN,CAZ,NIT,AMK, CED,CTR,COT,RIF \\
\hline 8 & Proteus spp. & LE,NIT,AMK GEN & & CAZ,CIP,CXM,CED,CTR,COT,RIF \\
\hline 9 & Proteus spp. & NIT,LE,CIP & RIF & GEN,CAZ,AMK,CXM,CED,CTR,COT \\
\hline 10 & E. coli & AMK,NIT,RIF & COT & GEN,CAZ,CIP,LE,CXM,CED,CTR \\
\hline 11 & E. coli & GEN,AMK,CTR & & CAZ,CIP,LE,NIT,CXM,CED,COT,RIF \\
\hline 12 & Proteus spp. & AMK++ & & $\begin{array}{l}\text { GEN,CAZ,CIP,LE,NIT,CXM,CED,CTR,C } \\
\text { OT,RIF }\end{array}$ \\
\hline 13 & Proteus spp. & $\mathrm{NIT}++, \mathrm{RIF}+$ & & GEN,CAZ,CIP,AMK,CXM,CED,CTR,COT \\
\hline 14 & Proteus spp. & NIT,RIF & & GEN,CAZ,CIP,AMK,CXM,CED,CTR,COT \\
\hline 15 & E. coli & AMK,NIT,GEN,CTR & & CAZ,CIP,CXM,CED,COT,RIF \\
\hline 16 & Proteus spp. & NIT,LE,CIP & & GEN,CAZ,AMK,CXM,CED,CTR,COT,RIF \\
\hline 17 & Proteus spp. & $\mathrm{AMK}+$ & & $\begin{array}{l}\text { GEN,CAZ,CIP,NIT,CXM,CED,CTR,COT, } \\
\text { RIF,LE }\end{array}$ \\
\hline 18 & $\begin{array}{l}\text { Pseudomonas } \\
\text { spp. }\end{array}$ & CTR,LE & & $\begin{array}{l}\text { GEN,CAZ,CIP,NIT,AMK,CXM,CED,COT, } \\
\text { RIF }\end{array}$ \\
\hline 19 & E. coli & CIP,LE & & $\begin{array}{l}\text { GEN,CAZ,NIT,AMK,CXM,CED,CTR,CO } \\
\text { T,RIF }\end{array}$ \\
\hline 20 & E. coli & CTR,CXM,AMK, GEN,NIT & & CAZ,CED,COT,RIF \\
\hline 21 & Proteus spp. & NIT,LE,CIP & & $\begin{array}{l}\text { GEN,CAZ,CIP,NIT,AMK,CXM,CED,CTR, } \\
\text { COT,RIF }\end{array}$ \\
\hline 22 & Proteus spp. & AMK,GEN,NIT & & CAZ,CIP,CXM,CED,CTR,COT,RIF \\
\hline 23 & E. coli & $\begin{array}{l}\text { COT,CIP,LE,CTR,AMK,CAZ } \\
\text {,NIT,CXM,GEN }\end{array}$ & & CED,RIF \\
\hline 24 & Proteus spp. & LE+ & & $\begin{array}{l}\text { GEN,CAZ,CIP,NIT,AK,CXM,CED,CTR,C } \\
\text { OT,RIF }\end{array}$ \\
\hline 25 & Proteus spp. & GEN,AMK,NIT & & CAZ,CIP,CXM,CED,CTR,COT,RIF \\
\hline 26 & $\begin{array}{l}\text { Pseudomonas } \\
\text { spp. }\end{array}$ & LE,AMK,CIP,GEN & & CAZ,NIT,CXM,CED,CTR,COT,RIF \\
\hline 27 & E.coli & NIT,LE,AMK & & GEN,CAZ,CIP,CXM,CED,CTR,COT,RIF \\
\hline 28 & E. coli & LE,CIP & & $\begin{array}{l}\text { GEN,CAZ,NIT,AMK,CXM,CED,CTR,CO } \\
\text { T,RIF }\end{array}$ \\
\hline 29 & E. coli & COT,NIT,LE,RIF & & GEN,CAZ,CIP,AMK,CXM,CED,CTR \\
\hline 30 & Proteus spp. & CTR,COT,NIT & & GEN,CAZ,CIP,AMK,CXM,CED,RIF \\
\hline
\end{tabular}

Gentamicin $=$ GEN, Cephradine $=$ CED, Cefuroxime $=\mathrm{CXM}$, Ceftadizime $=$ CAZ, Amikacin $=$ AMK, Nitrofurantoin $=$ NIT, Ciprofloxacin $=$ CIP, Levofloxacin $=$ LE, Rifampin $=$ RIF, Ceftriaxone $=$ CTR, Cotrimoxazole $=$ COT $+=$ Degree of sensitivity 
more fatal infections $(51,52)$. Drug resistant genes can be carried into other susceptible bacteria by plasmid, bacteriophage, transposons etc. If these elements are absent, resistance can also be occurred by random chromosomal mutations (53).

In our current research, multiple drug resistance were documented (Table 2) in cohort with the previous studies (14-21). 10 Proteus spp. isolates were found to be sensitive towards CTR, COT, NIT, GEN, AMK, LE, CIP and RIF antibiotics (Table 2). Among these antibiotics NIT, RIF and AMK showed better susceptibility than other antibiotics by showing larger clear zones in the Mueller Hinton agar medium. CED and CXM antibiotics were showed to be moderate and this indicates that these two antibiotics are going to be resistant in the upcoming days. One sample (sample no. 19) showed moderate activity for RIF. E. coli which wass the second predominant pathogen causing UTI in this study (found in 13 samples out of 30) showed susceptibility towards LE, GEN, NIT, AMK, CTR, CIP, CXM and RIF. All of the Proteus spp. were resistant to CAZ, COT etc. E. coli from sample no. 23 showed to most susceptibility towards most of the antibiotics and least resistance (resistant to 2 antibiotics only- CED, RIF). CTR, LE and AMK, GEN, NIT were best suited in killing Pseudomonas spp. from sample no. 18 and 26, respectively. Klebsiella spp. found only in sample no. 13 was sensitive to AMK, RIF, LE and resistant against GEN, CAZ, CIP, NIT, CXM, CED, CTR, COT (Table 2).

It is very important to prescribe antibiotics after antibiotic sensitivity test and it should be advised in appropriate dosage. The patients must be instructed correctly to take the medications just as prescribed and should also be informed properly about the deleterious effects of misuse of the antibiotics heading to the drug resistance which not only cause harm to the individual but also the people in surroundings (60).

\section{CONCLUSION}

Though urinary tract infection is a common phenomenon, the treatment procedure is becoming more complicated due to multi drug resistant pathogenic bacteria. Only a few antibiotics are still in susceptible condition. But the resistance toward these antibiotics could be an obvious condition for the future. Development of new drugs is a must and patients should be advised properly to take the antibiotic medication to control the condition of rapidly occurring resistance traits.

\section{ACKNOWLEDGEMENT}

Authors are thankful to the Department of Microbiology, Stamford University Bangladesh for all the technical help.

\section{REFERENCES}

1. Renuart AJ, Goldfarb DM, Mokomane M, Tawanana EO, Narasimhamurthy M, Steenhoff AP, et al. 2013. Microbiology of urinary tract infections in Gaborone, Botswana. PLoS ONE. 8 (3): e57776.

2. Schmiemann G, Kniehl E, Matejczyk KG, Pradier EH. 2010. Diagnosis of urinary tract infection- A systematic review. Dtsch Arztebl. Int. 107 (21): 361-367.

3. Rakaa L, Mulliqi-Osmani G, Berisha L. 2004. Etiology and susceptibility of urinary tract isolates in Kosova. Int. J. Antimicrob. agents. 23S1S2-S5.

4. Devillé WL, Yzermans JC, van Duijn NP, Bezemer PD, van der Windt DA, Bouter LM. 2004. The urine dipstick test useful to rule out infections- A meta-analysis of the accuracy. BMC Urol. 4: 4.

5. Raza S, Pandey S, Bhatt CP. 2011. Microbiological analysis of the urine isolates in Kathmandu Medical College, Teaching Hospital, Kathmandu, Nepal. Kathmandu Uni. Med. J. 36 (4): 295-7.

6. Garofalo CK, Hooton TM, Martin SM. 2007. Escerichia coli from urine of female pateints with urinary tract infections is competent for intracellular bacterial community formation. Infect. Immun. 75: 52-60.

7. El-Sweih N, Jamal W, Rotimi VO. 2008. Spectrum and antibiotic resistance of uropathogens isolated from hospital and community patients with urinary tract infections in two large hospitals in Kuwait. Med. Principl. pract. 14: 401-407.

8. Kolawale AS, Kolawale OM, Kandaki-Olukemi YT, Babatunde SK, Durowade KA, Kplawale CF. 2009. Prevalence of urinary tract infections among patients attending Dalhatu Araf Specialist Hospital, Lafia, Nasarawa State, Nigeria. Int. J. Med. Med. Sci. 1 (5): 163-1 67.

9. Abubakar EM. 2009. Antimicrobial susceptibility pattern of pathogenic bacteria causing urinary tract infections at the Specialist Hospital, Yola, Adamawa state, Nigeria. Journal of Clinical Medicine and Research. 1 (1): 1-8.

10. Farajnia S, Alikhani MY, Ghotaslou R, Naghili B, Nakhlband A. 2009. Causative agents and antimicrobial susceptibilities of urinary tract infections in the northwest of Iran. Int. J. Infect. Dis. 13: 140-144.

11. Cunha BA. 2009. Urinary Tract Infection, Females. Available at: http:// emedicine.medscape.com/article/233101-overview. Accessed 25 January, 2010.

12. Dulawa J. 2004. Urinary tract infection-2003. Ann. Acad. Med. Bialostoc. 49: 182-184.

13. Fihn SD. 2003. Acute uncomplicated urinary tract infection in women. N. Engl. J. Med. 349: 259-266.

14. Sarker UJ, Munna MS, Munshi SK. 2013. Microbiological profile of symptomatic and asymptomatic bacteriuria recovered from female patients with urinary tract infection. Stamford Journal of Microbiology. 3 (1): 34-37.

15. Noor AF, Shams F, Munshi SK, Rahman MM, Noor R. 2013. Prevalence and antibiogram profile of uropathogens isolated from hospital and community patients with urinary tract infections in Dhaka city. Journal of Bangladesh Academy of Sciences. 37 (1): 57-63.

16. Khan SA, Feroz F, Noor R. 2013. Study of extended spectrum $\beta$ lactamase producing bacteria from urinary tract infection from Dhaka city, Bangladesh. Tzu Chi Medical Journal. 25 (1): 39-42.

17. Hasan R, Acharjee M, Noor R. 2016. Prevalance of vancomycin resistant Staphylococcus aureus (VRSA) in methicillin resistant $S$. aureus (MRSA) strains isolated from burn wound infection. Tzu Chi Medical Journal. DOI: 10.1016/j.tcmj.2016.03.002

18. Noor R, Hasan MF, Rahman MM. 2014. Molecular characterization of the virulent microorganisms along with theirdrug resistant traits associated with the export quality frozen shrimps in Bangladesh. SpringerPlus. 3: 469

19. Alam SMS, Kalam MA, Munna MS, Munshi SK, Noor R. 2014. Isolation of pathogenic microorganisms from burn patients admitted in Dhaka medical College and Hospital and demonstration of their drug resistant traits. Asian Pacific Journal of Tropical Disease. 4 (5): 174-176.

20. Ahmed T, Baidya S, Sharma BC, Malek M, Das KK, Acharjee M, et al. 2013. Identification of drug resistant bacteria among export quality shrimp samples in Bangladesh. Asian J. Microbiol. Biotechnol. Envi. Sci. 15 (4): 31-36.

21. Dutta S, Hasan MR, Rahman F, Jilani MSA, Noor R. 2013. Study of antimicrobial susceptibility of clinically significant microorganisms isolated from selected areas of Dhaka, Bangladesh. Bangladesh Journal of Medical Science. 12 (1): 34-42.

22. Kripke C. 2005. Duration of therapy for women with uncomplicated UTI. Am. Fam. Physician. 72: 19-22.

23. National Committee for Clinical Laboratory Standards. 2000. Performance standards for antimicrobial disc susceptibility tests, $7^{\text {th }}$ ed. Wayne, Pennsylvania, USA. 
24. Wilson ML, Gaido L. 2004. Laboratory diagnosis of urinary tract infections in adult patients. Clin. Infect. Dis. 38: 1150-1158.

25. Bonadio M, Meini M, Spetaleri P, Gilgi C. 2001. Current microbiological and clinical aspects of urinary tract infections. Eur. J. Urol. 40: 439-445

26. Grude N, Tveten Y, Kristiansen BE. 2001. Urinary tract infections in Norway: bacterial etiology and susceptibility, a retrospective study of clinical isolates. Clin. Microbiol. Infect. 7: 543-547.

27. Sefton AM. 2000. The impact of resistance on the management of urinary tract infections. Int. J. Antimicrob. Agents. 16: 489-491.

28. Hendriksen RS, Trees EH, Pulsrikarn C, Pornruangwong S, Chaichana P, Svendsen CA, et al. 2012. Characterization of Salmonella enterica serovar Enteritidis isolates recovered from blood and stool specimens in Thailand. BMC Microbiology. 12: 92.

29. Mootsikapun P. 2007. Bacteremia in adult patients with AIDS in the north east in Thailand. International Journal of Infectious Diseases. 11: 226-231.

30. Ronald AR, Nicolle LE, Stamm E. 2001. Urinary tract infection in adults: Research priorities and strategies. Int. J. Antimicrob. Agents. 17: 343-348.

31. Obiogbolu CH, Okonko IO, Anyamere CO. 2009. Incidence of urinary tract infections (UTIs) among pregnant women in Akwa metropolis, Southeastern Nigeria. Sci. Res. Essays. 4: 820-824.

32. Scottish Intercollegiate Guidelines Network. 2006. Management of suspected bacterial urinary tract infection in adults.

33. Behzadi P, Behzadi E. 2008. The Microbial agents of urinary tract infections at central laboratory of Dr. Shariati Hospital, Tehran, IRAN. Turk. Klin. Tip. Bilim. 28: 445-449.

34. Howes DS. 2009. Urinary tract infection, female. Available at: http:// emedicine.medscape.com/article/778670-print. Accessed 25 January, 2010

35. Ayhan N, Basbug N, Ozturk S. 1988. Causative agents of urinary tract infections and sensitivity to antibiotics. Microbiol. Bull. 22: 215-221.

36. Ebie MY, Kandakai-Olukemi YT, Ayanbadejo J. 2001. Urinary tract infections in a Nigerian Military Hospital. Nig. J. Microbiol. 15: 31-37.

37. Tessema B, Kassu A, Mulu A, Yismaw G. 2007. Predominant isolates of urinary tract pathogens and their susceptibility patterns in Gonder Univesity Teaching Hospital, Northwest Ethiopia. Ethio. Med. J. 45: 6167.

38. Assefa A, Asrat D, Woldeamanuel Y, Hiwot Y, Abdella A, Melesse T. 2008. Bacterial profile and drug susceptibility pattern of urinary tract infection in pregnant women at Tikur Anbessa Specialized Hospital Addis Ababa, Ethiopia. Ethiop. Med. J. 46: 227- 35.
39. Dromigny JA, Nabeth P, Claude PGJD. 2002. Distribution and susceptibility of bacterial urinary tract infections in Dakar, Senegal. Int. J. Antimicrob. Agents. 20: 339-47.

40. Bi XC, Zhang B, Ye YK. 2009. Pathogen incidence and antibiotic resistance patterns of catheter-associated urinary tract infection in children. J. Chemother. 21: 661-665.

41. Khameneh ZR, Afshar AT. 2009. Antimicrobial susceptibility pattern of urinary tract pathogens. Saudi J. Kidney Dis. Transpl. 20: 251-253.

42. Chin BS, Kim MS, Han SH. 2011. Risk factors of all cause in hospital mortality among Korean elderly bacteremic urinary tract infection (UTI) patients. Arch. Gerontol. Geriatr. 52 (1): e50-5.

43. Zaheer R., Cook SR, Klima CL, Stanford K, Alexander T, Topp E, et al. 2013. Effect of subtherapeutic vs. therapeutic administration of macrolides on antimicrobial resistance in Mannheimia haemolytica and enterococci isolated from beef cattle. Front. Microbiol. 4: 133.

44. Morita Y, Tomida J, Kawamura Y. 2012. MexXY multidrug efflux system of Pseudomonas aeruginosa. Front. Microbiol. 3: 408.

45. Usui M, Nagai H, Hiki M, Tamura Y, Asai T. 2013. Effect of antimicrobial exposure on AcrAB expression in Salmonella enterica subspecies enteric serovar choleraesuis. Front. Microbiol. 4: 53.

46. Deng Z, Shan Y, Pan Q, Gao X, Yan A. 2013. Anaerobic expression of the gadE-mdtEF multidrug efflux operon is primarily regulated by the twocomponent system ArcBA through antagonizing the H-NS mediated repression. Front. Microbiol. 4: 194.

47. Baucheron S, Monchaux I, Le HS, Weill FX, Cloeckaert A. 2014. Lack of efflux mediated quinolone resistance in Salmonella enterica serovars Typhi and Paratyphi A. Front. Microbiol. 5: 12.

48. Roberts SA, Lawrence MS, Klimczak LJ, Grimm SA, Fargo D, Stojanov P, et al. 2013. An APOBEC cytidine deaminase mutagenesis pattern is widespread in human cancers. Nature Genetics. 45: 970-976.

49. Weinstein RA. 2001. Controlling antimicrobial resistance in hospitals: infection control and use of antibiotics. Emerg. Infect. Dis. 7: 188-192.

50. Anonymous. 2002. European antimicrobial resistance surveillance system. EARSS Annual Report 2002

51. Arthur M, Courvalin P. 1993. Genetics and mechanisms of glycopeptide resistance in enterococci. Antimicrob. Agents Chemother. 37: 1563-1571.

52. Goossens H. 1999. The epidemiology of vancomycin-resistant enterococci Curr. Opin. Infect. Dis. 12: 537-541.

53. Lee C, Cho IH, Jeong BC, Lee SH. 2013. Strategies to minimize antibiotic resistance. Int. J. Environ. Res. Public Health. 10 (9): 4274-4305. 